\title{
Energy analysis, numerical simulations and intervention proposals for a NZEB industrial building: the "Loccioni Leaf Lab" case study.
}

\author{
Ettore Stamponi ${ }^{1}$, Nicola Lattanzi $^{2}$, Francesco Giorgini ${ }^{3}$, Fabio Serpilli ${ }^{4}$, Sergio Montelpare ${ }^{5}$ and Elisa Moretti $^{*}$ \\ ${ }^{1}$ CIRIAF - Interuniversity Research Centre, University of Perugia, Via G. Duranti 63 (Perugia, Italia) \\ ${ }^{2}$ Department of Civil and Environmental Engineering - University of Perugia, Via G. Duranti 93 (Perugia, Italia) \\ ${ }^{3}$ Loccioni, Via Fiume 16, Angeli di Rosora (Ancona, Italia) \\ ${ }^{4}$ Università Politecnica delle Marche - Department of Industrial Engineering and Mathematical Sciences, Via Brecce Bianche \\ (Ancona, Italy) \\ ${ }^{5}$ Department of Engineering and Geology - Università degli Studi "G. d'Annunzio" Chieti - Pescara, Viale Pindaro, 4265127 \\ (Pescara, Italy) \\ ${ }^{6}$ Department of Engineering - University of Perugia, Via G. Duranti 93 (Perugia, Italia)
}

\begin{abstract}
The object of this paper is the "Loccioni Leaf Lab", an industrial nZEB connected to a thermal and electric smart grid. Having nZEB buildings connected to a smart grid offers the possibility of maximizing the benefits that can be obtained by optimal regulation of the grid itself, providing excellent economic and energy results. The case study, which hosts offices and workers operating on test benches, features high performance envelope, solar photovoltaic systems, groundwater heat pumps and a hightechnology control and monitoring system. In order to analyse HVAC-related energy consumptions, the building was modelled using DesignBuilder and EnergyPlus software. The annual dynamic simulations for the assessment of building thermal-energy performance were carried out using available monitored weather data (2019). The model was validated according to ASHRAE guidelines, comparing the outputs of the software with data collected and stored by Company internal database. In the validation process, mean indoor air temperatures of several zones and heating and cooling energy consumptions were considered as key outputs. The validated model has then been used to suggest optimization strategies and to analyse the results obtained with proposed interventions in terms of energy saving.
\end{abstract}

\section{Introduction}

Due to their impact on global energy consumption and greenhouse gas emissions, efficiency in buildings has become an increasingly important issue in the recent past. To achieve the environmental targets imposed by international agreements, the European Union has developed strict regulations on Nearly-Zero Energy Buildings [1].

The aim of the present paper is to analyse the energy performance of a high-efficiency industrial building, by means of experimental data and numerical analysis [23]. A weather file representative of the real climatic conditions during the experimental campaign was implemented, in order to compare the simulation results and the experimental data and to validate the model [4].
Finally, thanks to the validated model, the influence of different optimization strategies on thermal comfort and energy performance was preliminarily evaluated.

\section{Case Study}

The Loccioni Group is a Company born in 1968 in Angeli di Rosora, a little town in central Italy in Marche region where the headquarters is located. Today the Company is present in 5 countries (US, Germany, China, Japan, India) and has installations in over 50 countries around the world. The site, named Leaf Community, is near Esino river. The campus consists of 6 buildings, connected by an electric and thermal smart grid that allows to better manage the consumption and the production from the renewable energy power plants.

\footnotetext{
* Corresponding author: elisa.moretti@unipg.it
} 
In this work has been studied the Leaf Lab building. The Leaf Lab is a Near-Zero Energy Building (NZEB) of $6000 \mathrm{~m}^{2}$ total floor area (Fig. 1). The building envelope is highly insulated and with an elevated level of building automation and control systems (BACS) [5].

The HVAC system is composed of ground water source heat pumps (COP 4.8, EER 6.2). The HVAC is coupled to a thermal storage water tank of about $150 \mathrm{~m}^{3}$, to store the power not directly used in medium seasons in particular.

The lighting of the building and its outdoor spaces is completely with LED lights. The lighting control is automatic with presence sensors and illumination sensors used to exploit the contribution of daylight.

In the envelope of the building, some windows open automatically, controlled by the management system, to obtain natural free cooling during the night [6]. In the roof of the building is installed a photovoltaic generator system of $236 \mathrm{~kW}_{\mathrm{p}}$. Exceeding electrical energy is stored by the micro-grid of the community, which involve PV generators on other buildings of the group and five hydropower stations [7].

Energy systems are managed by MyLeaf platform, which allows monitoring of measurements and advanced control systems [8]. A full description of the Leaf Lab is reported in [9].

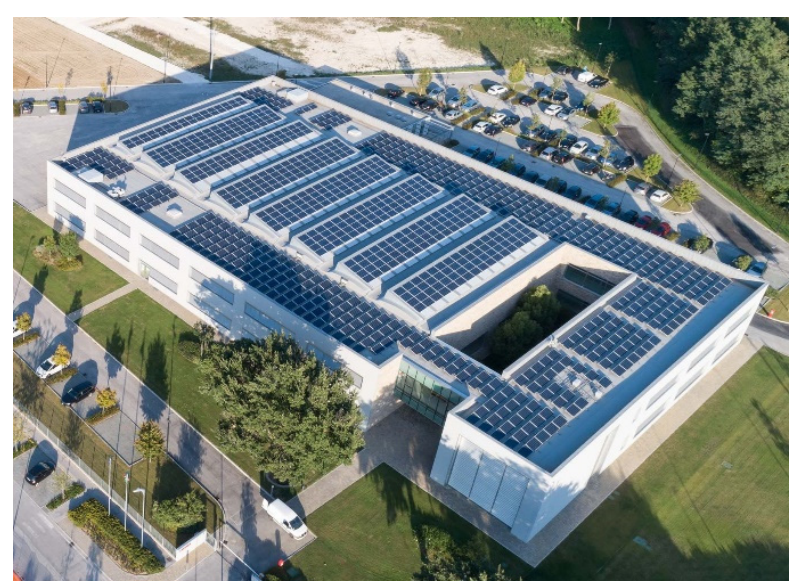

Fig. 1. The "Loccioni Leaf lab" building

\section{Methods}

To evaluate the energy performance improvement associated to the implementation of the proposed strategies, building dynamic energy simulation was carried out. Consumption data for the model has been obtained from MyLeaf platform. This data has been used to create a model of the building using the software esignBuilder and EnergyPlus [10]. Firstly, the building performance was validated on the basis ofthe thermal zone air temperature. Secondly, the whole buildingsystem model was validated based on the energy demand for the whole building.

The model has been validated using ASHRAE guidelines 14-2014 [11] and it has then been used to evaluate the impact of interventions proposed during the analysis phase. Results were compared in terms of energy demands for cooling and heating.

\subsection{Data collection}

Due to Covid-19 emergency, it has not been possible to collect data through monitoring campaigns inside the building. For this reason, all the necessary information has been obtained from an internal database which allows to storage all the data collected through the monitoring system installed in the buildings of the Campus. In this database the data are organised in "channels" that describe the information and the instrumentation used to collect it. All data are collected with a time step of 15 minutes. In this way, it has been possible to obtain information regarding the power and thermal energy consumption of the building in 2019, indoor air temperatures, hours of operations of the HVAC system, and weather data. The monitoring system did not work correctly in some days, and these periods had not been taken into account while analysing the case study and, especially, while determining the value of validation indexes.

\subsection{Thermodynamic model}

The case study has been modelled using the software DesignBuilder and EnergyPlus. Initially, an EnergyPlus Weather Format Data file for 2019 was created using the tool "Weather Statistics and Conversions". Then all the data collected has been used to model building envelope, occupancy, internal loads, HVAC system, hours of operations, natural and mechanical ventilation, and solar shading management. A high number of simulations have been carried out to ensure that the parameters implemented in the model could reasonably represent the real case.

The 3D representation of the Leaf Lab simulation model is presented in Figure 2.

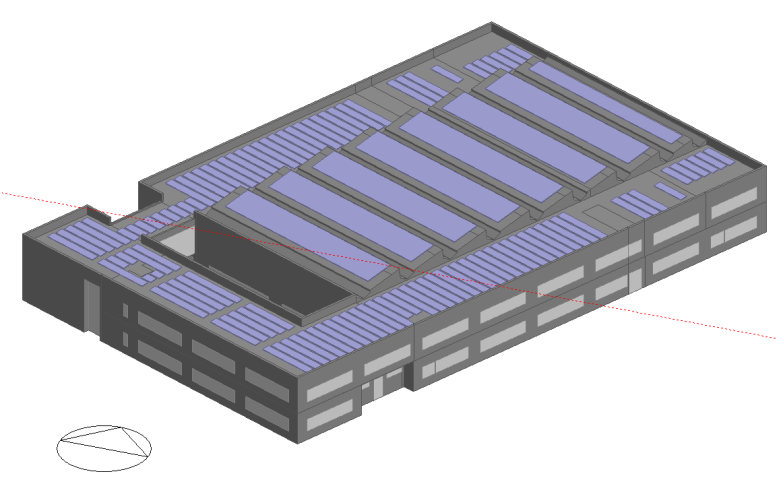

Fig. 2. 3D model of the investigated building

\section{Results and discussion}

\subsection{Energy analysis from experimental data}

Data from Myleaf platform were analysed in order to highlight the impact of HVAC system in terms of electric energy consumptions (Figure 3). HVAC represents $38,4 \%$ of total electric demand, with a total consumption of approximately $220000 \mathrm{kWh}$ (about $30000 \mathrm{kWh}$ in July and December). 


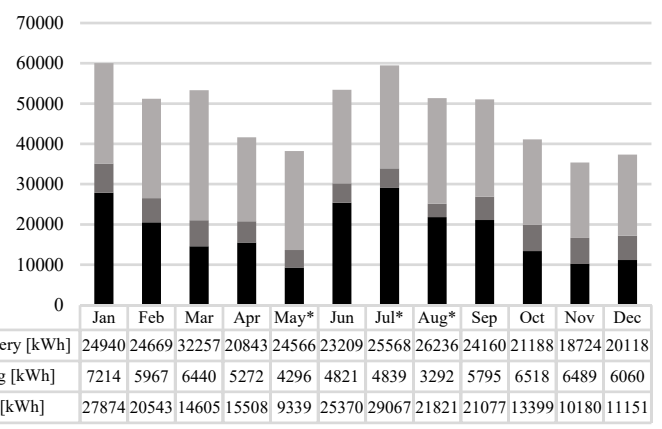

Fig. 3. Monthly electric energy consumption for Leaf Lab building (2019)

\subsection{Model validation}

ASHRAE guidelines 14-2014 [11] propose the following numeric parameters to validate a thermodynamic model:

1. Normalized Mean Bias Error - NMBE

$$
N M B E=\frac{1}{\bar{m}} \cdot \frac{\sum_{i=1}^{n}\left(s_{i}-m_{i}\right)}{n-p} \times 100[\%]
$$

2. Coefficient of Variation of the Root Mean Square Error - CV(RMSE)

$$
C V(R M S E)=\frac{1}{\bar{m}} \cdot \sqrt{\frac{\sum_{i=1}^{n}\left(s_{i}-m_{i}\right)^{2}}{n-p}} \times 100[\%]
$$

3. Coefficient of determination $-\mathrm{R}^{2}$

$$
R^{2}=\left(\frac{n \cdot \sum_{i=1}^{n} s_{i} m_{i}-\sum_{i=1}^{n} s_{i} \cdot \sum_{i=1}^{n} m_{i}}{\sqrt{\left(n \cdot \sum_{i=1}^{n} s_{i}^{2}-\left(\sum_{i=1}^{n} s_{i}\right)^{2}\right) \cdot\left(n \cdot \sum_{i=1}^{n} m_{i}^{2}-\left(\sum_{i=1}^{n} m_{i}\right)^{2}\right)}}\right)^{2}
$$

Where:

$\bar{m}=$ mean value of observed data

$S_{i}=$ simulated values

$m_{i}=$ observed values

$n=$ number of observed data

$p=$ number of adjustable parameters

ASHRAE also suggests the intervals to consider the model validated on hourly basis or on monthly basis (Table 1).

Table 1. Validation criteria

\begin{tabular}{lll}
\hline Index & $\begin{array}{l}\text { Hourly } \\
\text { criteria }\end{array}$ & $\begin{array}{l}\text { Monthly } \\
\text { criteria }\end{array}$ \\
\hline NMBE & $-10 \% \div 10 \%$ & $-5 \% \div 5 \%$ \\
CV $(\mathrm{RMSE})$ & $\leq 30 \%$ & $\leq 15 \%$ \\
$\mathrm{R}^{2}$ & $\geq 0,75$ & $\geq 0,75$ \\
\hline
\end{tabular}

Initially, the model has been validated considering indoor air temperatures. Three zones have been selected: the production laboratory, which represents the biggest zone in volume, and the office areas on the building longer sides (East and West). As shown in table 2 and figure 4, the model is validated on hourly basis considering indoor air temperatures.

Table 2. Validation indexes for different thermal zones

\begin{tabular}{llll}
\hline Index & $\begin{array}{l}\text { Office } \\
\text { (east) }\end{array}$ & $\begin{array}{l}\text { Office } \\
\text { (west) }\end{array}$ & $\begin{array}{l}\text { Production } \\
\text { laboratory }\end{array}$ \\
\hline NMBE & $0,8 \%$ & $-1,2 \%$ & $2,5 \%$ \\
CV(RMSE) & $4,7 \%$ & $4,6 \%$ & $7,4 \%$ \\
$\mathrm{R}^{2}$ & 0,89 & 0,90 & 0,82 \\
\hline
\end{tabular}

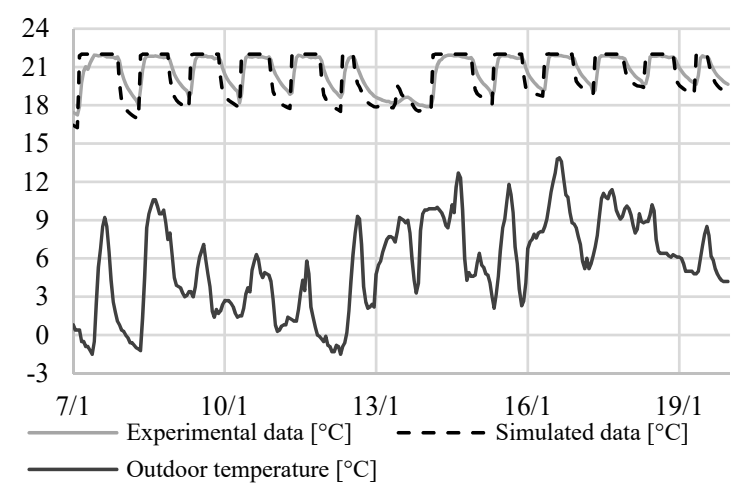

Fig. 4. Comparison between simulated and experimental indoor air temperatures for offices (East side).

Considering the goals of the study (to simulate the energy impact of proposed strategies), analysis and validation of the model have been carried out focussing on energy consumption. The model could not be considered validated on hourly basis when considering total energy demands for heating and cooling (Table 3). This is due to the behaviour of lower consumption months such as April, May, September, and October. In these months, hourly differences have a bigger impact on $\mathrm{CV}(\mathrm{RMSE})$ parameter due to the lower mean value of observed consumption data. Higher consumption months, such as June, July, August, and December, result instead validated. The comparison between the hourly measured cooling energy demands and the simulated ones for a typical summer period is shown in figure 5 .

Table 3. Validation indexes (hourly basis) in terms of energy demands for different periods

\begin{tabular}{lllll}
\hline Index & $\begin{array}{l}\text { Total } \\
\text { Heating }\end{array}$ & $\begin{array}{l}\text { Total } \\
\text { Cooling }\end{array}$ & $\begin{array}{l}\text { July } \\
\text { Cooling }\end{array}$ & $\begin{array}{l}\text { December } \\
\text { Heating }\end{array}$ \\
\hline NMBE & $4,7 \%$ & $-3,5 \%$ & $-3,1 \%$ & $-7,9 \%$ \\
CV(RMSE) & $48,5 \%$ & $30,6 \%$ & $22,3 \%$ & $28,0 \%$ \\
$\mathrm{R}^{2}$ & 0,81 & 0,86 & 0,93 & 0,92 \\
\hline
\end{tabular}

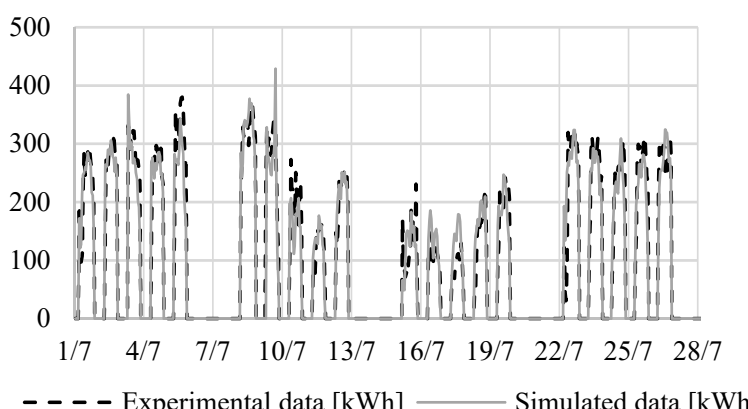

Fig. 5. Comparison between simulated and experimental data for the month of July 
For this reason, the model has been validated on monthly basis considering thermal energy consumptions (Table 4 and figure 6). The results do not consider the month of March: this month shows an energy consumption too high in the simulation (due to unusual internal gains which are not implemented in the model because of lack of information), and therefore it has been not taken into account in the validation and in the simulation of intervention proposals.

Table 4. Validation indexes (monthly basis) for total heating and cooling energy demand

\begin{tabular}{llll}
\hline Index & $\begin{array}{l}\text { ASHRAE } \\
\text { criteria }\end{array}$ & $\begin{array}{l}\text { Heating } \\
\text { demand }\end{array}$ & $\begin{array}{l}\text { Cooling } \\
\text { demand }\end{array}$ \\
\hline NMBE & $-5 \% \div 5 \%$ & $-0,4 \%$ & $-2,4 \%$ \\
CV(RMSE) & $\leq 15 \%$ & $13,5 \%$ & $6,9 \%$ \\
$\mathrm{R}^{2}$ & $\geq 0,75$ & 0,98 & 0,98 \\
\hline
\end{tabular}
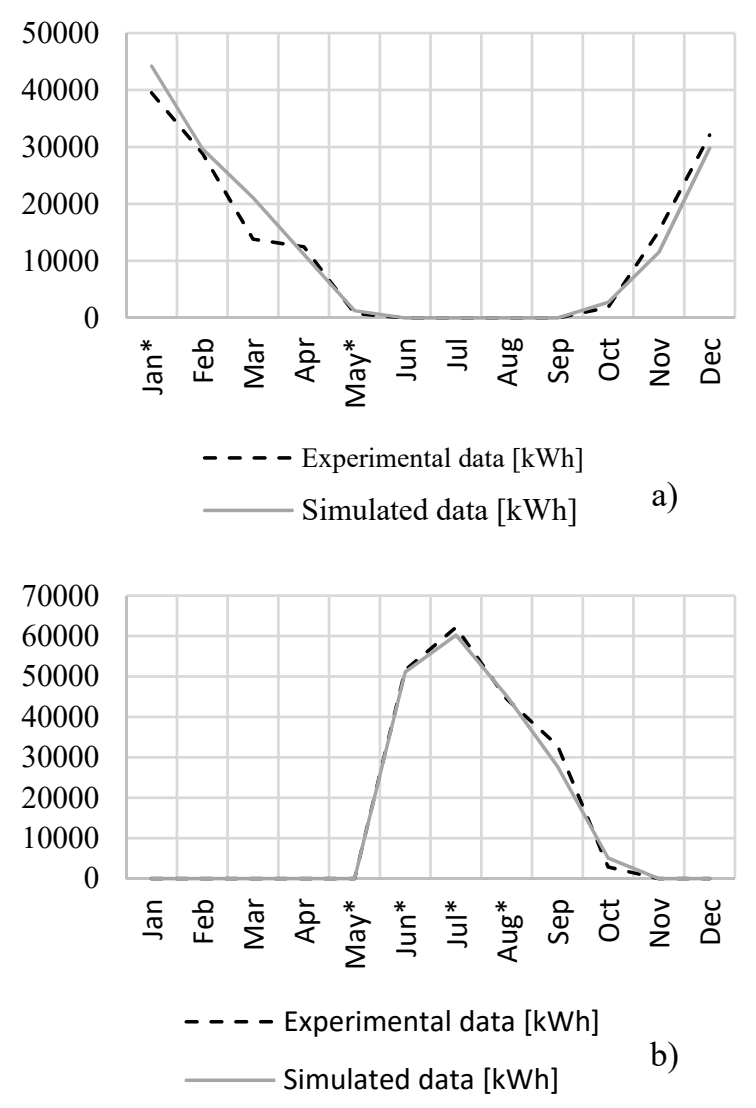

Fig. 6. Comparison between simulated and experimental data: a) Heating energy demand; b) cooling energy demand

In conclusion, considering that the model is validated on monthly basis and the general behaviour is correctly simulated even on hourly basis except for the lower consumption months (which have a low impact in terms of general consumption while having a high impact on the validation parameters), the model has been considered validated and it has been used to simulate the variation on HVAC energy demands resulting from the proposed interventions.

\subsection{Optimization strategies}

During the first phase of the work, the energy analysis of the building led to some considerations regarding aspects of management that could possibly be improved and optimized. The case study is a nZEB construction with a complex HVAC system, and for this reason only interventions on the management aspect have been proposed: due to the characteristics of the building, other types of intervention would have too high payback period.

\subsubsection{Solar shadings management}

To ensure the highest possible number of natural lighting avoiding the risk of glaring, the solar shadings work through an algorithm based on illuminance sensors on the four external walls of the building and on solar azimuth. The algorithm has been modified through years of experience to match the best behavior in terms of thermal comfort. It has been observed, however, that the algorithm works in the same way for every day of the week. It has been proposed to modify the algorithm on Sunday, leaving the shadings always open during the heating period. In this way it is possible to take advantage of the free solar intake, raising indoor temperatures. Solar gain lowers energy demand for heating during the next day, resulting in a 2,4\% energy saving in the heating period ( $3.838 \mathrm{kWh})$. The proposed solution has already been implemented by the Company and it will therefore be possible to evaluate its actual impact in the near future.

\subsubsection{Free cooling}

In the building, natural ventilation is regulated through an algorithm that enables the mechanical opening of some windows based on indoor and outdoor air temperatures. However, this algorithm is disabled during the night, because the opening of windows during night-time led to the entry of insects inside the building. In this way, low external temperatures during summer nights are not exploited and it has been possible to verify, using the model, that natural ventilation has in these conditions a very low impact on energy consumption. In order to take advantage of low temperature, it has been proposed to turn on mechanical ventilation during the night and ensure a free cooling of internal zones. It is possible to obtain in this way energy savings, particularly lowering the peaks of consumption during the first hours of the next day. However, this benefit has to be compared with the electric energy consumption due to the fans used to force external air into the building. Using the model, it has been possible to find the best configuration to maximize the net energy saving, which is enabling mechanical ventilation with an external temperature lower than $19^{\circ} \mathrm{C}$ and only during 03:00 - 07:00 in the months of July and August. In this way, it is possible to save $302 \mathrm{kWh}$ of electricity during the cooling period. Energy consumption, however, happens during the night with no production of photovoltaic plant. Implementing this intervention could therefore lead to an energy saving but with an economic 
loss. For these reasons, it is recommended to the Company to further investigate the possible benefits of free cooling during the next months, when the fans should be turned on anyway due to the guidelines regarding Covid-19 emergency published by AiCARR [12-13].

\subsubsection{Indoor Air recirculation}

The HVAC system is turned on earlier than working hours (set at 08:00). Using an algorithm based on indoor and outdoor temperatures, the system ensures an early start to reach the desired setpoint at the beginning of working time. Considering the HVAC system, it is possible during the periods of non-occupancy to enable the recirculation of indoor air and avoiding the conditioning of outdoor air. In this way, the setpoint condition can be reached with less energy consumption, and there is no risk of a negative impact on inside comfort conditions considering the absence of people. Simulations of this hypothesis have been performed from June to December, considering that the management of the HVAC system varied from the first to the second heating period due to entering in operations of the thermal smart grid in November: simulating the intervention from January to May would have led to a miscalculation of possible benefit. According to the model, this intervention can lead to a thermal energy saving of $18.804 \mathrm{kWh}$ during the cooling period ( $8 \%$ of total energy) and $5.786 \mathrm{kWh}$ during the second heating period (13\% of total energy).

\section{Conclusion and future development}

In this work, the industrial nZEB "Leaf Lab" of the Loccioni Company was investigated. After analysing the energy consumptions and the usage profile of the building, a dynamic model was created. Given the complexity of the building and the HVAC system, modelling was extremely complicated.

Overall, the proposed interventions will not produce significant economic savings, but this obviously derives from the investigated building: the nZEB buildings are in fact designed and built to allow maximum energy savings. However, the proposed interventions can be considered cost-free and therefore reasonable despite the low impact in absolute terms. It is important to note that, since the building is linked with thermal and electric smart grid, even the slightest savings can have a positive impact on the management of the entire grid. Furthermore, some of the recommended interventions can be extended to all the other buildings of the Loccioni Campus, thus increasing the total savings.

Finally, future developments will further improve the building numerical model in order to use the validated model in combination with meteorological forecasting tools. By verifying the impact on the model, it will be possible to propose management methods based on the outdoor conditions expected trend to minimize energy consumption by developing a new switch-on algorithm.
Authors wish to thank UNIVPM - DIISM Department for their support in the preliminary numerical analyses. The authors would also like to thank the Loccioni group (https://www.loccioni.com) for the willingness to provide information and for the hospitality received during the inspections at Angeli di Rosora. Special thanks to Team Facility for the valuable support provided during the monitoring campaign.

\section{References}

1. International Energy Agency. Available online: https://www.iea.org/topics/buildings (accessed on 11 June 2019).

2. A.K. Athienitis, W. O'Brien, Modeling, Design, and Optimization of Net-Zero Energy Buildings, Wiley Online Library: Hoboken, NJ, USA, (2015).

3. V. Harish, A. Kumar, A review on modelling and simulation of building energy systems. Renew. Sustain. Energy Rev. (2016). 56, 1272-1292.

4. C. Buratti, E. Moretti, E. Belloni, F. Cotana, Unsteady simulation of energy performance and thermal comfort in non-residential buildings. Building and Environment (2013), 59, 482-491.

5. EN 15232-1 2017. Energy Performance of Buildings - Energy performance of buildings - Part 1: Impact of Building Automation, Controls and Building Management.

6. C. Ghiaus, F. Allard, Potential for free-cooling by ventilation. Solar Energy (2006), 80, 402-413.

7. E. Provata, D. Kolokotsa, S. Papantoniou, M. Pietrini, A. Giovannelli, G. Romiti, Development of optimization algorithms for the Leaf Community microgrid. Renew. Energy (2015), 74, 782-795.

8. MyLeaf Platform - Loccioni Group. Available online: https://https://myleaf2.loccioni.com

9. N. Kampelis, K. Gobakis, V. Vagias, D. Kolokotsa, L. Standardi, D. Isidori, C. Cristalli, F. Montagnino, F. Paredes, P. Muratore, et al. Evaluation of the performance gap in industrial, residential \& tertiary near-Zero energy buildings. Energy Build. (2017), 148, 58-73.

10. EnergyPlus ${ }^{\mathrm{TM}}$, Engineering Reference Documentation Version 9.1.0, National Renewable Energy Laboratory, 2019. Available online: https://energyplus.net (accessed on 12 August 2019).

11. M \& V Guidelines: Measurement and Verification for Performance-Based Contracts Version 4.0. Available online: https://www.energy.gov/sites/prod/files/2016/01/f 28/mv_guide_4_0.pdf

12. AICARR. Protocol for risk reduction of SARSCoV2-19 diffusion with the aid of existing air conditioning and ventilation systems. Available online:https://www.aicarr.org/Pages/Normative/F OCUS COVID-19 IT.aspx

13. WHO, 2020, "Getting your workplace ready for COVID-19”, World Health Organization. 